\title{
BMJ
}

\section{Thigh circumference and risk of heart disease and premature death: prospective cohort study}

\author{
Berit L Heitmann, professor, director of research, ${ }^{1}$ head of section, health promotion in hospitals, ${ }^{2}$ Peder \\ Frederiksen, statistician ${ }^{1}$
}

${ }^{1}$ Research Unit for Dietary Studies, Institute of Preventive Medicine,

Copenhagen University Hospital, DK-1357 Copenhagen K, Denmark

${ }^{2}$ Research Centre for Prevention and Health, Glostrup University Hospital, DK-2600 Glostrup,

Denmark

Correspondence to: B L Heitmann, Research Unit for Dietary Studies, Institute of Preventive Medicine,

Østre Søgade 20, Copenhagen University Hospital, DK-1357

Copenhagen K, Denmark

blh@ipm.regionh.dk

Cite this as: $B M J$ 2009;339:b3292 doi:10.1136/bmj.b3292

\section{ABSTRACT}

Objective To examine associations between thigh circumference and incident cardiovascular disease and coronary heart disease and total mortality.

Design Prospective observational cohort study with Cox proportional hazards model and restricted cubic splines. Setting Random subset of adults in Denmark.

Participants 1436 men and 1380 women participating in the Danish MONICA project, examined in 1987-8 for height, weight, and thigh, hip, and waist circumference, and body composition by impedance.

Main outcome measures 10 year incidence of

cardiovascular and coronary heart disease and 12.5 years of follow-up for total death.

Results A small thigh circumference was associated with an increased risk of cardiovascular and coronary heart diseases and total mortality in both men and women. A threshold effect for thigh circumference was evident, with greatly increased risk of premature death below around $60 \mathrm{~cm}$. Above the threshold there seemed to be no additional benefit of having larger thighs in either sex. These findings were independent of abdominal and general obesity, lifestyle, and cardiovascular risk factors such as blood pressure and lipid concentration.

Conclusion A low thigh circumference seems to be associated with an increased risk of developing heart disease or premature death. The adverse effects of small thighs might be related to too little muscle mass in the region. The measure of thigh circumference might be a relevant anthropometric measure to help general practitioners in early identification of individuals at an increased risk of premature morbidity and mortality.

\section{INTRODUCTION}

Several studies have shown a U-shaped association between body mass index (BMI) and mortality, suggesting both a high and a low BMI are associated with premature death. ${ }^{1}$ More recent data suggest that while the increased risk seen with a high BMI is mirrored by the risk associated with a high body fat mass, the risk observed at low BMI seems more closely linked to the risk associated with low fat free mass than low fat mass. ${ }^{23} \mathrm{~A}$ larger hip circumference relative to BMI and waist circumference seems a strong inverse predictor of both morbidity and mortality. ${ }^{4-7}$ In this context, a recent study suggested that lower body muscle mass is particularly related to the development of type 2 diabetes. Indeed, studies have reported that insulin resistance could be provoked in lower body muscle, such as leg muscle, but not in arm muscle, ${ }^{89}$ suggesting that the size of the lower body muscle might have great relevance for developing type 2 diabetes. These findings are in line with results from a study among patients with chronic obstructive pulmonary disease, a condition characterised by wasting of muscle, particularly of the lower extremities, which found that the cross sectional area of mid-thigh muscle was a far better predictor of mortality than BMI. ${ }^{10}$ Lower body fat, however, might also offer cardioprotection through endocrine secretion of various adipokines, such as adiponectine, a peptide with apparent anti-inflammatory properties. ${ }^{11-13}$ In particular, low subcutaneous fat in the thighs leads to adverse glucose and lipid metabolism. ${ }^{14}$

We do not know whether thigh size is independently related to cardiovascular and coronary heart disease or premature death among the general population. We therefore examined associations between thigh circumference and early total mortality and morbidity from heart disease. We hypothesised that a threshold effect would be evident, above which no further protection from large thighs would be evident because of a sufficient thigh tissue mass.

\section{METHODS}

\section{Sample}

Of those invited to participate, 2987 (83\%) people born in $1922,1932,1942$, or 1952, and with a mean age of 50.1 (SD 10.8) in men and 49.7 (SD 10.9) in women at examination in 1987-8, had their height, weight, and thigh, hip, and waist circumference measured as part of the Danish MONICA (monitoring trends in and determinants of cardiovascular disease) project, ${ }^{15}$ an international study conducted under the auspices of the World Health Organization. ${ }^{16}$ Body fat mass and lean body mass was estimated from impedance measures, by using an equation developed previously for estimating body composition specifically for this population sample. ${ }^{17} \mathrm{We}$ included in this study only the 1436 men and 1380 women who were free from 
coronary heart disease, stroke, or cancer at baseline $(63$ excluded) and had complete information on all covariates (103 excluded).

\section{Anthropometric measures}

Body weight was measured to the nearest $0.1 \mathrm{~kg}$ with a lever balance with participants wearing underwear or light clothing. Height without shoes was measured to the nearest $1 \mathrm{~cm}$. Thigh, waist, and hip circumferences were measured to the nearest $1 \mathrm{~cm}$. Thigh circumference was measured directly below the gluteal fold of the right thigh. Waist circumference was measured mid-way between the lower rib margin and the iliac crest, while hip circumference was measured at the point over the buttocks yielding the maximum circumference. All anthropometric measurements were taken in accordance with WHO standards. ${ }^{18}$

\section{Bioelectrical impedance measurements}

A BIA-103 RJL system analyser (RJL Systems, Detroit) was used to measure electrical impedance, according to the instructions provided by the manufacturer. The measurement was done with tetra-polar electrode placement with participants lying relaxed on a couch, limbs slightly abducted from the body. Electrodes were placed on the dorsal surfaces of the right hand and foot, at the distal metacarpals and metatarsals, respectively, and between the distal prominence of the radius and the ulna at the wrist and the medial and lateral malleoli at the ankle. An equation for estimating body fat from impedance had been developed earlier based on a subgroup by using measurements of total body water and potassium to specifically fit this random sample of Danes. ${ }^{17}$ The equation is body fat $(\mathrm{kg})=0.819$ body weight $(\mathrm{kg})-0.279$ height $^{2} /$ resis- $^{-}$ tance $\left(\mathrm{cm}^{2} / \mathrm{ohm}\right)-0.064$ sex $\times$ body weight $(\mathrm{kg})+$ 0.077 age (years) -0.231 height $(\mathrm{cm})+14.941$. (Sex is coded as 1 for men and 0 for women). Percentage body fat was calculated from measures of body fat mass and body weight.

\section{End points}

Participants initially free from coronary heart disease, stroke, and cancer were followed up until 9 December 2002 through personal identification numbers at the National Registers of Hospital Discharge and Death Registry for an average of 12.5 years for all causes of death, and for 10 years until January 1999 for incident cardiovascular and coronary heart diseases. ICD-8 (international classification of diseases, eighth revision) codes 390-458 and ICD-10 (10th revision) codes I00I52, and I60-I99 were used to evaluate incidence of cardiovascular disease. For the incidence of coronary heart disease ICD- 8 codes 410-414 and ICD-10 codes I20-I25 were used. Data on all participants could be retrieved from the registries.

\section{Covariates}

For leisure time physical activity participants placed themselves in one of four groups: (1) your leisure time activities are sedentary, such as sitting, reading, watching television, going to the cinema; (2) you walk and sometime cycle, and you are active at least four hours a week (such as building, table tennis, and bowling); (3) you are active in sports, such as running, swimming, playing tennis or badminton, etc, at least three hours a week, or you often do heavy gardening or spare time work; (4) you are an elite sportsperson, swimming, playing football, or long distance running, etc, several times a week. We merged groups (3) and (4) because of insufficient numbers in group (4).

Participants also reported whether they were current smokers, ex-smokers, or never smokers. Smokers reported daily tobacco consumption, type of tobacco, and duration of smoking, and ex-smokers were asked about duration of smoking and time since quitting. Pack years of smoking were calculated for all current smokers as the number of years of smoking $\times$ daily tobacco consumption (g) divided by 20 . Participants reported their weekly consumption of beer, wine, and spirits. For the analyses we divided units per week into $\leq 1,2-6,7-13,14-27,28-41$, and $>41$. In addition, education was assessed with questions about the highest grade or year of regular schooling and the highest degree earned, and classified into 0-7 years, 8-11 years, and $>12$ years; and women gave information about whether they had entered menopause.

Systolic blood pressure was measured with a London School of Hygiene sphygmomanometer, with one of three different cuffs. Duplicate measurements were done in the left arm after minimum of five minutes' rest in a supine position. Means of duplicate measures were calculated. Total serum cholesterol and triglyceride concentrations $(\mathrm{mmol} / \mathrm{l})$ were measured from blood samples drawn after a 12 hour overnight fast. Commercial enzymatic methods (Boehringer Mannheim, GmbH, Mannheim, Germany) were used to analyse for the lipids.

\section{Statistical analyses}

We used Kruskal-Wallis tests and $\chi^{2}$ tests to compare the distribution of the variables between groups of survivors and those who died and Cox proportional hazard regression model with age during follow-up as underlying time scale. ${ }^{19}$ This means that the baseline hazard represents the age specific mortality rate for a reference individual, and the estimated hazard ratios are mortality rate ratios relative to the age specific mortality rate of the reference individual. As the cohort comprised four different birth cohorts, the three oldest birth cohorts were considered late entries.

Separate analyses were performed for men and women. We fitted a series of four models examining the association between thigh circumference and total mortality and cardiovascular and coronary heart disease under different adjustments schemes. The first model (the basic model) included thigh circumference, smoking, education, physical activity, and menopause in women. Model 2 additionally adjusted for body fat percentage and height. Model 3 additionally adjusted for BMI and waist circumference. Model 4 additionally 
adjusted for systolic blood pressure, total cholesterol and triglyceride concentrations, and alcohol consumption. Finally, we explored the effects of smoking and residual confounding from amount smoked during a life time (pack years). Cubic splines with four knots placed at the 5th, 35th, 65th, and 95th centiles to allow for non-linear effects of the continuous effect variables as well as covariates. ${ }^{20}$ The splines were restricted to be linear below the first knot point and above the last knot point. The proportional hazards assumption implies that the effects of the covariates are constant over time - that is, do not vary with age. We examined this assumption with Schoenfeld residuals $^{21}$ and found no indication of problems regarding non-proportionality. The curves had a shape indicating a threshold effect and in the final analyses we assumed that the log hazard below a given threshold was a linear function of thigh circumference. Among all such models we used the model with the lowest value of Akaike information criterion as an estimate of the threshold.

\section{RESULTS}

Over 12.5 years of follow-up 257 men (crude rate/ $1000=3.3)$ and 155 women (8.0) died. In the 10 years to January 1999, 263 men (9.4) and 140 women (0.1) experienced incident cardiovascular disease, and 103 men (7.3) and 34 women (2.4) experienced incident coronary heart disease. Table 1 gives information on the anthropometric variables and lifestyle by vital status among men and women. Compared with the men who died during follow-up, baseline BMI, body fat, hip and waist circumferences, age, blood pressure, and lipid concentrations, as well as pack years and prevalence of smokers, heavy drinkers, and inactivity were generally lower for the men who survived, whereas baseline fat free mass, thigh circumference, and height were greater for the survivors. Similar findings were seen for the women, though not significantly so for BMI, percentage body fat, hip and waist circumference, and alcohol consumption.

Men and women with thigh circumferences below median values had lower BMI, body fat, fat free mass, waist circumference, and height. Men with smaller thighs had slightly lower triglyceride concentrations (median $1.1 \mathrm{mmol} / \mathrm{l}$ (95\% confidence interval 0.6 to $2.6 \mathrm{mmol} / \mathrm{l})$ v $1.3 \mathrm{mmol} / \mathrm{l}(0.6$ to $3.5 \mathrm{mmol} / \mathrm{l}))$. They tended to be older (55.7 years ( 35.7 to 66.3 years) $v$ 45.9 years (35.6 to 65.8 years)), more were smokers $(60.3 \%$ v 49.2\%, $\mathrm{P}<0.001)$, and median pack years (27.9 years (7.7 to 59.3 years) v 23.0 years (6.4 to 52.1 years)) were slightly higher. Systolic blood

Table 1 | Descriptive statistics of anthropometric variables and lifestyle factors by sex and vital status. Figures are medians (5th and 95th centiles) unless stated otherwise

\begin{tabular}{|c|c|c|c|c|c|c|}
\hline & \multicolumn{2}{|c|}{ Men } & \multirow[b]{2}{*}{$P$ value } & \multicolumn{2}{|c|}{ Women } & \multirow[b]{2}{*}{$P$ value } \\
\hline & $\begin{array}{c}\text { Censored } \\
(n=1179 / 82 \%)\end{array}$ & $\begin{array}{c}\text { Dead } \\
(n=257 / 18 \%)\end{array}$ & & $\begin{array}{c}\text { Censored } \\
(n=1225 / 89 \%)\end{array}$ & $\begin{array}{c}\text { Dead } \\
(n=155 / 11 \%)\end{array}$ & \\
\hline $\mathrm{BMI}\left(\mathrm{kg} / \mathrm{m}^{2}\right)$ & 25.3 (20.8 to 32.0 ) & $26.2(21.0$ to 33.4$)$ & $<0.001$ & 23.6 (19.2 to 32.5$)$ & $24.2(17.8$ to 35.8$)$ & 0.4 \\
\hline Body fat (kg) & $18.3(9.2$ to 32.8$)$ & 20.6 (11.1 to 25.1$)$ & $<0.001$ & 19.4 (10.0 to 37.4$)$ & 21.2 (7.9 to 41.1$)$ & 0.7 \\
\hline Fat free mass $(\mathrm{kg})$ & $60.1(51.2$ to 71.3$)$ & $58.0(47.6$ to 69.3$)$ & $<0.001$ & $44.3(37.5$ to 51.9$)$ & $41.8(35.1$ to 51.1$)$ & $<0.001$ \\
\hline Body fat (\%) & 23.5 (13.9 to 33.3 ) & 26.8 (16.8 to 35.8$)$ & $<0.001$ & 30.9 (19.1 to 43.9$)$ & 33.5 (18.0 to 46.0$)$ & $<0.001$ \\
\hline Thigh circumference $(\mathrm{cm})$ & $55.5(48.5$ to 63.0$)$ & 53.5 (46.5 to 61.0 ) & $<0.001$ & $56.0(48.5$ to 66.5$)$ & $54.0(44.0$ to 66.0$)$ & $<0.001$ \\
\hline Hip circumference $(\mathrm{cm})$ & 98.0 (89.5 to 109.5$)$ & 99.0 (90.0 to 111.0 ) & $<0.05$ & $97.0(87.0$ to 114.0$)$ & 96.0 (83.5 to 115.5$)$ & 0.3 \\
\hline Waist circumference $(\mathrm{cm})$ & $90.0(77.0$ to 109.0$)$ & 94.5 (79.5 to 113.0$)$ & $<0.001$ & 76.5 (65.5 to 98.0$)$ & $79.0(62.0$ to 105.0$)$ & 0.2 \\
\hline Height (cm) & 1.76 (1.66 to 1.88$)$ & $1.74(1.62$ to 1.84$)$ & $<0.001$ & 1.64 (1.55 to 1.75$)$ & 1.61 (1.51 to 1.70$)$ & $<0.001$ \\
\hline Age (years) & $45.9(35.6$ to 65.9$)$ & 65.5 (45.5 to 66.6$)$ & $<0.001$ & 46.0 (35.6 to 66.0$)$ & $56.4(45.5$ to 66.5$)$ & $<0.001$ \\
\hline Systolic blood pressure $(\mathrm{mm} \mathrm{Hg})$ & $122(105$ to 153$)$ & $136(110$ to 177$)$ & $<0.001$ & 117 (99 to 151) & $128(101$ to 167$)$ & $<0.001$ \\
\hline Cholesterol (mmol/l) & $6.1(4.5$ to 8.1$)$ & $6.3(4.6$ to 8.2$)$ & $<0.001$ & $5.8(4.3$ to 8.0$)$ & $6.8(5.0$ to 8.5$)$ & $<0.001$ \\
\hline Triglycerides (mmol/l) & 1.2 (0.6 to 3.2$)$ & 1.3 (0.7 to 3.6$)$ & $<0.001$ & $1.0(0.5$ to 2.1$)$ & 1.3 (0.6 to 2.5$)$ & $<0.001$ \\
\hline Pack years & $22.5(6.7$ to 53.1$)$ & $39.0(14.3$ to 64.6$)$ & $<0.001$ & $18(4.5$ to 40.0$)$ & $22.9(7.7$ to 50.8$)$ & $<0.001$ \\
\hline No (\%) of smokers & $616(52.2)$ & $171(66.5)$ & $<0.001$ & $557(45.5)$ & $96(61.9)$ & $<0.001$ \\
\hline No (\%) physically inactive & $238(20.2)$ & $83(32.3)$ & \multirow{3}{*}{$<0.001$} & $323(26.4)$ & $53(34.2)$ & \multirow{3}{*}{$<0.05$} \\
\hline No (\%) medium active & $647(54.9)$ & $129(50.2)$ & & $754(61.6)$ & $89(57.4)$ & \\
\hline No (\%) active & $294(24.9)$ & $45(17.5)$ & & $148(12.0)$ & $13(8.4)$ & \\
\hline No (\%) postmenopause & - & - & - & $576(47.0)$ & $124(80.0)$ & $<0.001$ \\
\hline No (\%) completed elementary school & $341(71.7)$ & $128(50.2)$ & $<0.001$ & $384(68.7)$ & $87(43.9)$ & $<0.001$ \\
\hline \multicolumn{7}{|l|}{ No (\%) of drinkers by No of units/week: } \\
\hline$\leq 1$ & $129(10.9)$ & $37(14.4)$ & \multirow{6}{*}{$<0.001$} & $418(34.2)$ & $62(40.0)$ & \multirow{6}{*}{$<0.001$} \\
\hline $2-6$ & $336(28.5)$ & $62(24.1)$ & & $492(40.2)$ & $53(34.2)$ & \\
\hline $7-13$ & $300(25.4)$ & $53(20.6)$ & & $208(17.0)$ & $19(12.3)$ & \\
\hline $14-27$ & $289(24.5)$ & $59(23.9)$ & & $85(6.9)$ & $14(9.0)$ & \\
\hline $28-41$ & $86(7.3)$ & $23(9.0)$ & & $13(1.1)$ & $4(2.6)$ & \\
\hline$>41$ & $39(3.3)$ & $23(8.9)$ & & $8(0.7)$ & $3(1.9)$ & \\
\hline
\end{tabular}

BMI=body mass index. 
Table 2 | Hazard ratios (95\% confidence intervals) for associations between thigh circumference and total mortality for 1436 men aged 35-65 followed for 12.5 years

\begin{tabular}{|c|c|c|c|c|}
\hline $\begin{array}{l}\text { Centile of thigh } \\
\text { circumference }(\mathrm{cm})\end{array}$ & Model $1^{*}$ & Model $2 \dagger$ & Model 3‡ & Model 4爪 \\
\hline $.5(46.5)$ & 1.59 (1.11 to 2.28$)$ & 2.62 (1.83 to 3.76 ) & 2.53 (1.74 to 3.69 ) & 2.23 (1.47 to 3.39$)$ \\
\hline $5(48.0)$ & 1.38 (1.05 to 1.82$)$ & 2.14 (1.63 to 2.81$)$ & 2.11 (1.54 to 2.89$)$ & $1.90(1.35$ to 2.67$)$ \\
\hline $10(49.5)$ & 1.21 (0.98 to 1.50$)$ & 1.75 (1.42 to 2.17 ) & 1.76 (1.34 to 2.32 ) & 1.61 (1.21 to 2.15$)$ \\
\hline $25(52.0)$ & 02 (0.86 to 1.21$)$ & 1.30 (1.09 to 1.53$)$ & 1.32 (1.07 to 1.64$)$ & 1.26 (1.01 to 1.57$)$ \\
\hline $50(55$. & 1 & 1 & 1 & 1 \\
\hline $75(58.0)$ & $1.09(0.91$ to 1.29$)$ & 0.84 (0.71 to 1.00$)$ & 0.81 (0.66 to 1.01$)$ & 0.83 (0.67 to 1.04$)$ \\
\hline $90(61.0)$ & 1.14 (0.86 to 1.51$)$ & 0.73 (0.55 to 0.97$)$ & 0.70 (0.48 to 1.03$)$ & 0.70 (0.46 to 1.06$)$ \\
\hline $95(63.0)$ & $1.16(0.75$ to 1.79$)$ & 0.67 (0.43 to 1.03$)$ & 0.64 (0.36 to 1.14$)$ & 0.62 (0.33 to 1.16$)$ \\
\hline $97.5(64.0)$ & 1.17 (0.69 to 1.98$)$ & 0.64 (0.38 to 1.08$)$ & 0.62 (0.31 to 1.23$)$ & $0.58(0.28$ to 1.24$)$ \\
\hline
\end{tabular}

*Adjusted for smoking, physical activity, and education.

†Additionally to * adjusted for body fat percentage and body height. P<0.001, likelihood ratio test for effect.

$\ddagger$ Additionally to * adjusted for BMI (body mass index) and waist circumference. P $<0.001$, likelihood ratio test for effect.

IAdditionally to $\ddagger$ adjusted for alcohol, systolic blood pressure, total cholesterol, and triglycerides. P<0.01, likelihood ratio test for effect.
Tables 2-7 show the predicted hazard ratios and confidence intervals for various centiles in the distribution of thigh circumference (the 2.5th, 5th, 10th, 25th, 50th, 75th, 90th, 95th, and 97.5th centiles) in relation to total death and cardiovascular and coronary heart diseases for men and women. The reference hazard ratio is for those with a median thigh circumference. Results are given for basic models (model 1) with adjustment for smoking, education, physical activity levels, and menopausal status (for women); additional adjustment for percentage body fat and height (model 2); and additional adjustment for BMI and waist circumference (model 3). Model 4 was also adjusted for alcohol intake, systolic blood pressure, and total cholesterol and triglyceride concentrations. In models 2 and 3, effects of thigh circumference were independently related to total death and cardiovascular and coronary heart diseases for men and to total death for women. A smaller thigh circumference was also related to cardiovascular disease in women (model 2 but not model 3), but associations with coronary heart disease did not reach significance. Inclusion of total cholesterol and triglyceride concentrations, systolic blood pressure, and alcohol consumption weakened associations slightly, but the general effects of thigh circumference remained significant for total mortality and cardiovascular disease (men only). Stepwise analyses showed that associations between thigh circumference and the end points were attenuated slightly by the inclusion of blood pressure, whereas inclusion of lipids or consumption of alcohol gave virtually similar results (data not shown). There were no significant interactions between age groups (all $\mathrm{P}>0.05$ ), suggesting that associations with thigh circumference were similar for younger and older people (data not shown).

Figure 1 show the relation between thigh circumference and the hazard ratio for total death in men and women. The independent inverse relations became stronger in the adjusted analyses compared with the basic analyses for both men and women. For a given $\mathrm{BMI}$ and waist circumference, or percentage fat mass and height, men and women with smaller thighs had an increased risk of early death compared with those with larger thighs. Similar hazards were apparent for both sexes and irrespective of adjustment for percentage fat mass and height or BMI and waist circumference.

In both men and women, there was a threshold effect in the curves for all end points, suggesting the existence of a critically low thigh circumference. This threshold was $62 \mathrm{~cm}$ for both men and women in relation to total mortality, $56 \mathrm{~cm}$ in relation to cardiovascular and coronary heart diseases for men, and $68 \mathrm{~cm}$ in relation to cardiovascular disease for women, and $60 \mathrm{~cm}$ in relation to coronary heart disease for women. Above these thresholds, the protective effect of having larger thighs on survival and morbidity from cardiovascular and coronary heart diseases was no longer related to the size of the thighs, whereas below the threshold the risk was greatly increased.

Figure 2 shows the relation between thigh circumference and the hazard ratio for total death from model 3 circumference. Model 1 adjusted for smoking status, education, physical activity, and menopause in women; model 2 additionally adjusted for baseline BMI and waist circumference; model 3 additionally adjusted for body fat $\%$ and body height 
Table 3 | Figures are hazard ratios ( $95 \%$ confidence intervals) for associations between thigh circumference and total mortality for 1380 women aged 35-65 followed for 12.5 years

\begin{tabular}{|c|c|c|c|c|}
\hline $\begin{array}{l}\text { Centile of thigh } \\
\text { circumference }(\mathrm{cm})\end{array}$ & Model $1^{*}$ & Model $2 \dagger$ & Model 3‡ & Model 4爪 \\
\hline $5(46.0)$ & 2.35 (1.60 to 3.45$)$ & 2.98 (1.58 to 5.62$)$ & 2.73 (1.38 to 5.41$)$ & 2.20 (1.07 to 4.54$)$ \\
\hline $5(48.0)$ & 1.91 (1.44 to 2.53$)$ & 2.38 (1.47 to 3.86$)$ & 2.35 (1.42 to 3.90$)$ & 2.00 (1.17 to 3.41$)$ \\
\hline $10(49.5)$ & 1.63 (1.29 to 2.06$)$ & 2.01 (1.37 to 2.96$)$ & 2.10 (1.42 to 3.11$)$ & 1.85 (1.22 to 2.81$)$ \\
\hline $25(52.0)$ & 1.29 (1.06 to 1.56$)$ & 1.51 (1.16 to 1.97$)$ & 1.67 (1.28 to 2.17$)$ & 1.56 (1.19 to 2.05$)$ \\
\hline $50(55.5)$ & 1 & $t$ & 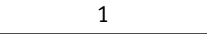 & 1 \\
\hline $75(59.5)$ & 0.89 (0.69 to 1.16$)$ & $0.71(0.51$ to 0.99$)$ & 0.59 (0.42 to 0.83$)$ & 0.63 (0.44 to 0.89$)$ \\
\hline $90(63.5)$ & 0.93 (0.67 to 1.30$)$ & 0.65 (0.40 to 1.06$)$ & $0.53(0.32$ to 0.86$)$ & $0.60(0.36$ to 1.00$)$ \\
\hline $95(66.5)$ & $1.02(0.63$ to 1.64$)$ & $0.66(0.34$ to 1.29$)$ & $0.56(0.29$ to 1.11$)$ & $0.66(0.32$ to 1.36$)$ \\
\hline $97.5(68.5)$ & 1.08 (0.58 to 2.01$)$ & $0.67(0.30$ to 1.54$)$ & 0.59 (0.25 to 1.39$)$ & $0.72(0.29$ to 1.77$)$ \\
\hline
\end{tabular}

*Adjusted for smoking, physical activity, education, and menopause. P 0.001 , likelihood ratio test for effect. †Additionally to * adjusted for body fat percentage and body height. P $<0.001$, likelihood ratio test for effect. $\ddagger$ Additionally to * adjusted for BMI (body mass index) and waist circumference. P 0.01 , likelihood ratio test for effect.

TAdditionally to $\ddagger$ adjusted for alcohol, systolic blood pressure, total cholesterol, and triglycerides. P<0.05, likelihood ratio test for effect.

and model 4 in men and women. The associations were attenuated only slightly by the inclusion of alcohol intake, systolic blood pressure, and total cholesterol and triglyceride concentrations. The shape of the curves was essentially similar before and after adjustment. Also, associations stratified by smoking or never smoking showed similar inverse associations, with greater hazard rates for those with smaller thighs for both sexes. Figure 3 shows the relation between thigh circumference and the hazard ratio for total death from model 3 according to smoking status, before and after adjustment for pack years from information on daily tobacco consumption and duration of smoking, in men and women. The hazard ratios seemed smaller among never smokers than among smokers, but the difference did not reach significance. Further adjustment for pack years among the smokers attenuated the association between thigh circumference and the end points slightly among men. Among female smokers, the associations between thigh circumference and the end points became slightly stronger after adjustment for pack years.

Table 4 | Figures are hazard ratios (95\% confidence intervals) for associations between thigh circumference and cardiovascular disease from 1436 men aged 35-65 followed for 10 years

\begin{tabular}{|c|c|c|c|c|}
\hline $\begin{array}{l}\text { Centile of thigh } \\
\text { circumference }(\mathrm{cm})\end{array}$ & Model 1* & Model $2 \dagger$ & Model $3 \ddagger$ & Model 4ף \\
\hline $2.5(46.5)$ & 1.25 (0.85 to 1.85$)$ & 1.98 (1.34 to 2.92 ) & 2.30 (1.62 to 3.26$)$ & 2.03 (1.35 to 3.03$)$ \\
\hline $5(48.0)$ & 1.14 (0.85 to 1.52$)$ & 1.70 (1.27 to 2.27$)$ & $1.96(1.46$ to 2.63$)$ & 1.73 (1.25 to 2.41$)$ \\
\hline $10(49.5)$ & 1.04 (0.84 to 1.28$)$ & 1.47 (1.19 to 1.82$)$ & 1.67 (1.29 to 2.16$)$ & 1.49 (1.13 to 1.96$)$ \\
\hline $25(52.0)$ & 0.94 (0.80 to 1.10$)$ & 1.18 (1.01 to 1.38$)$ & 1.30 (1.06 to 1.59$)$ & 1.19 (0.96 to 1.46$)$ \\
\hline $50(55.0)$ & 1 & 1 & 1 & 1 \\
\hline $75(58.0)$ & 1.19 (1.00 to 1.41$)$ & $0.95(0.80$ to 1.13$)$ & 0.88 (0.71 to 1.09$)$ & $0.96(0.77$ to 1.19$)$ \\
\hline $90(61.0)$ & 1.38 (1.08 to 1.76$)$ & 0.99 (0.77 to 1.26$)$ & $0.90(0.65$ to 1.25$)$ & $1.01(0.72$ to 1.43$)$ \\
\hline $95(63.0)$ & 1.51 (1.07 to 2.13$)$ & 1.04 (0.74 to 1.46$)$ & 0.96 (0.62 to 1.49$)$ & 1.07 (0.67 to 1.72$)$ \\
\hline $97.5(64.0)$ & 1.58 (1.05 to 2.38$)$ & $1.06(0.71$ to 1.60$)$ & 0.99 (0.60 to 1.65$)$ & 1.11 (0.64 to 1.93$)$ \\
\hline
\end{tabular}

*Adjusted for smoking, physical activity, and education.

†Additionally to * adjusted for body fat percentage and body height. P<0.05, likelihood ratio test for effect. $\ddagger$ Additionally to * adjusted for BMI (body mass index) and waist circumference. P $<0.01$, likelihood ratio test for effect.

TAdditionally to $\ddagger$ adjusted for alcohol, systolic blood pressure, total cholesterol, and triglycerides. P<0.05, likelihood ratio test for effect.
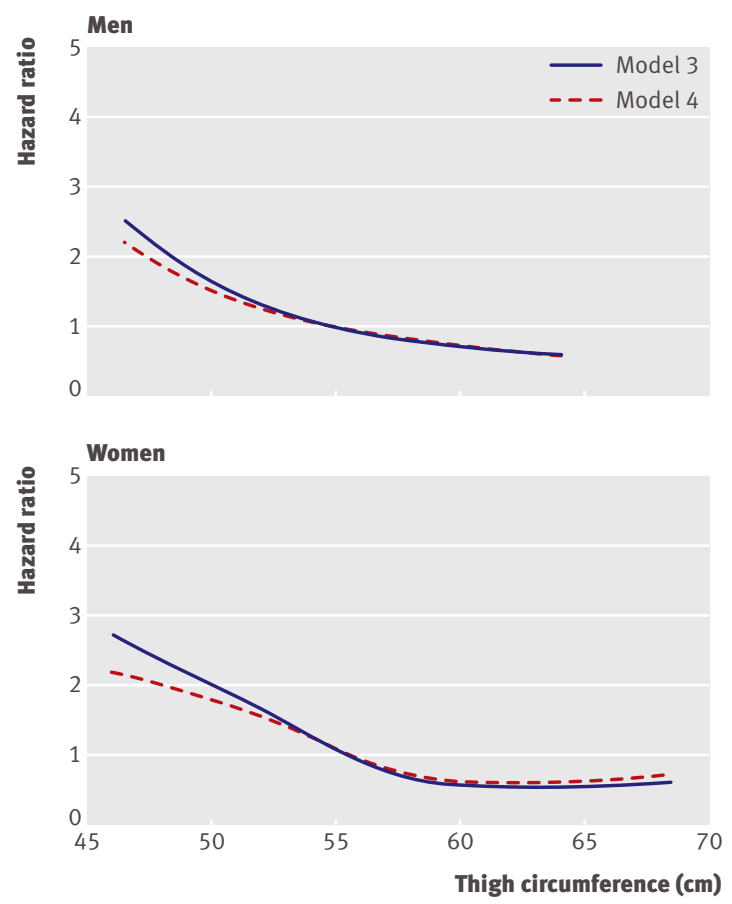

Fig 2 | Hazard ratio for total death according to thigh circumference among 1436 men and 1380 women. Model 3 adjusted for smoking status, education, physical activity, menopause in women, BMI, and waist circumference; model 4 additionally adjusted for alcohol intake, systolic blood pressure, and total cholesterol and triglyceride concentrations

\section{DISCUSSION}

We found independent inverse associations between thigh circumference and total death and morbidity from cardiovascular disease in both men and women that were particularly evident when thigh circumference was below a threshold of around $60 \mathrm{~cm}$. Above this threshold there did not seem to be any further benefit of having larger thighs. The increased risk associated with smaller thigh circumferences was seen independently of percentage body fat mass and height or of waist circumference and BMI for all end points, suggesting that for any given degree of general and abdominal obesity, smaller thighs are a disadvantage to health and survival for both sexes. Further analyses with adjustment for systolic blood pressure, total cholesterol and triglyceride concentrations, and alcohol weakened the associations only slightly, and suggested that associations between thigh size and the end points were not mediated by differences in these variables. Some power was lost, however, by the inclusion of more covariates and the associations between thigh circumference and particularly coronary heart disease did not remain significant. Our analyses indicated that associations were independent of heavy smoking as measured by pack years, and associations seemed to be stronger for smokers than for never smokers, but this difference was not significant, probably because of too few end points in the two groups of the stratified analysis. 
Table 5 | Figures are hazard ratios (95\% confidence intervals) for associations between thigh circumference measures and cardiovascular disease for 1380 women aged 35-65 followed for 10 years

\begin{tabular}{|c|c|c|c|c|}
\hline $\begin{array}{l}\text { Centile of thigh } \\
\text { circumference }(\mathrm{cm})\end{array}$ & Model $1^{*}$ & Model $2 \dagger$ & Model 3‡ & Model 4T \\
\hline $2.5(46.0)$ & $1.53(0.96$ to 2.44$)$ & 2.35 (1.15 to 4.8$)$ & $2.04(0.96$ to 4.33$)$ & 1.90 (1.86 to 4.22$)$ \\
\hline $5(48.0)$ & 1.34 (0.96 to 1.87$)$ & 1.91 (1.12 to 3.26$)$ & $1.73(1.00$ to 3.00$)$ & 1.66 (0.92 to 2.97$)$ \\
\hline $10(49.5)$ & 1.21 (0.93 to 1.57$)$ & 1.64 (1.08 to 2.50$)$ & $1.53(1.00$ to 2.34$)$ & $1.49(0.96$ to 2.33$)$ \\
\hline $25(52.0)$ & 1.05 (0.86 to 1.29$)$ & $1.29(0.98$ to 1.71$)$ & $1.26(0.96$ to 1.65$)$ & 1.26 (0.95 to 1.66$)$ \\
\hline $50(55.5)$ & 1 & 1 & 1 & 1 \\
\hline $75(59.5)$ & $1.01(0.77$ to 1.32$)$ & $0.80(0.57$ to 1.13$)$ & $0.81(0.57$ to 1.14$)$ & $0.82(0.57$ to 1.16$)$ \\
\hline $90(63.5)$ & $0.92(0.63$ to 1.33$)$ & 0.65 (0.38 to 1.10$)$ & $0.66(0.39$ to 1.11$)$ & $0.72(0.42$ to 1.24$)$ \\
\hline $95(66.5)$ & 0.82 (0.46 to 1.45$)$ & 0.55 (0.26 to 1.18$)$ & 0.57 (0.26 to 1.23$)$ & 0.68 (0.31 to 1.50$)$ \\
\hline $97.5(68.5)$ & $0.76(0.36$ to 1.61$)$ & $0.50(0.19$ to 1.30$)$ & 0.51 (0.19 to 1.38$)$ & $0.65(0.24$ to 1.78$)$ \\
\hline
\end{tabular}

*Adjusted for smoking, physical activity, education, and menopause.

†Additionally to * adjusted for body fat percentage and body height. P<0.05, likelihood ratio test for effect.

$\ddagger$ Additionally to * adjusted for BMI (body mass index) and waist circumference.

IAdditionally to $\ddagger$ adjusted for alcohol, systolic blood pressure, total cholesterol, and triglycerides.

\section{Comparison with other studies}

Our findings are in line with earlier observations of a threshold effect for a low total fat free mass, ${ }^{2}$ further supporting that the apparent threshold effect for the risk related to a low thigh circumference might depend primarily on too little fat free mass in the area rather than on too little fat or a small pelvic size. Insulin sensitivity might be lowered when leg muscle is small, ${ }^{8914}$ and lack of subcutaneous fat might also influence glucose and lipid metabolism in a negative way. ${ }^{14} \mathrm{We}$ did not take measures of insulin sensitivity or glucose tolerance and therefore cannot examine if associations between thigh circumference and the end points were partly mediated by disturbances in glucose metabolism. Adjustment for total cholesterol and triglyceride concentrations, however, made little difference to our results, suggesting that differences in lipids were not the primary pathway linking larger thighs to survival. Indeed, even if our observed associations between smaller thigh size and mortality were independent of total body fat, lack of subcutaneous fat in the thigh might still be relevant. In light of the fact that the

Table 6 | Figures are hazard ratios (95\% confidence intervals) for associations between thigh circumference and coronary heart disease for 1436 men aged 35-65 followed for 10 years

\begin{tabular}{|c|c|c|c|c|}
\hline $\begin{array}{l}\text { Centile of thigh } \\
\text { circumferences } \\
(\mathrm{cm})\end{array}$ & Model 1* & Model $2 \dagger$ & Model 3‡ & Model 4ף \\
\hline $2.5(46.5)$ & 1.35 (0.77 to 2.37$)$ & 2.33 (1.33 to 4.11$)$ & 2.58 (1.53 to 4.35$)$ & $2.38(1.30$ to 4.36$)$ \\
\hline $5(48.0)$ & 1.17 (0.76 to 1.80$)$ & 1.91 (1.24 to 2.94$)$ & 2.12 (1.35 to 3.33$)$ & 1.91 (1.15 to 3.17$)$ \\
\hline $10(49.5)$ & $1.03(0.73$ to 1.44$)$ & 1.57 (1.12 to 2.20$)$ & 1.75 (1.17 to 2.62$)$ & $1.54(0.99$ to 2.39$)$ \\
\hline $25(52.0)$ & 0.89 (0.68 to 1.17$)$ & $1.18(0.91$ to 1.55$)$ & $1.30(0.93$ to 1.81$)$ & 1.15 (0.81 to 1.62$)$ \\
\hline $50(55.0)$ & 1 & 1 & 1 & 1 \\
\hline $75(58.0)$ & $1.21(0.92$ to 1.58$)$ & $0.92(0.70$ to 1.21$)$ & $0.87(0.62$ to 1.23$)$ & 0.97 (0.68 to 1.39$)$ \\
\hline $90(61.0)$ & $1.20(0.77$ to 1.88$)$ & $0.82(0.53$ to 1.28$)$ & $0.85(0.48$ to 1.50$)$ & 0.89 (0.48 to 1.65$)$ \\
\hline $95(63.0)$ & $1.13(0.56$ to 2.30$)$ & 0.75 (0.37 to 1.52$)$ & $0.86(0.38$ to 1.95$)$ & 0.82 (0.33 to 2.05$)$ \\
\hline $97.5(64.0)$ & $1.10(0.46$ to 2.59$)$ & $0.72(0.30$ to 1.70$)$ & $0.87(0.33$ to 2.28$)$ & $0.79(0.27$ to 2.34$)$ \\
\hline
\end{tabular}

*Adjusted for smoking, physical activity, and education.

†Additionally to * adjusted for body fat percentage and body height. P<0.05, likelihood ratio test for effect.

$\ddagger$ Additionally to * adjusted for BMI (body mass index) and waist circumference. P $<0.05$, likelihood ratio test for effect.

ๆAdditionally to $\ddagger$ adjusted for alcohol, systolic blood pressure, total cholesterol, and triglycerides. composition of soft tissue on the thigh differs between the sexes, it is interesting that associations were more or less similar for women and men and that the threshold did not differ substantially. This raises the question as to whether there is a sex difference in the health risk related to lower body peripheral fat and lower body muscle. Previous studies showing a stronger relation between hip circumference and coronary end points, as well as total mortality, in women than in men, support such a sex difference, though none of these previous studies considered total or regional body composition. $^{4-6}$

\section{Strengths and limitations of study}

The fact that associations were independent of percentage body fat as well as abdominal obesity suggests that the risk with smaller thighs might be associated with too little muscle mass in the region. It is a limitation that we did not measure tissue composition of the thighs to study this question. Residual confounding by smoking or exercise is a possibility, though the fact that the risk associated with smaller thighs was seen both for smokers and non-smokers and that the increased risk among smokers was independent of confounding from pack years suggests that residual confounding from smoking was not a major problem. For exercise, the possibility remains of residual confounding. Previous studies, however, have shown that the measure of physical activity we used correlates well with maximum oxygen volume capacity ${ }^{22}$ and has a
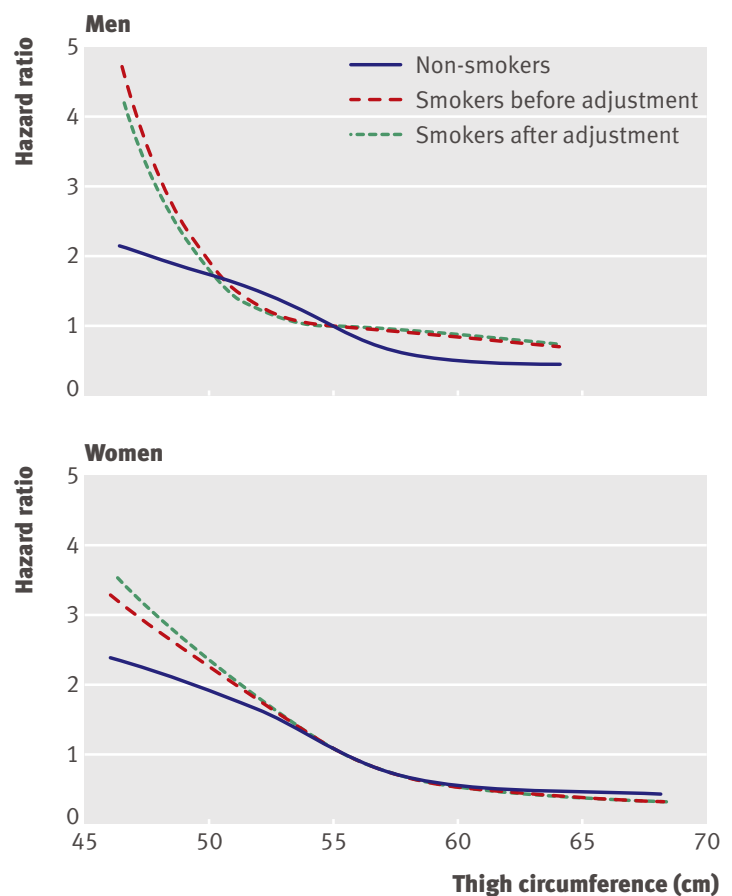

Fig 3 | Hazard ratio for total death according to thigh circumference among 1436 men and 1380 women. Model 3 for non-smokers, adjusted for education, physical activity, menopause in women, BMI, and waist circumference; and for smokers, before and after additional adjustment for pack years 
Table 7 | Figures are hazard ratios (95\% confidence intervals) for associations between thigh circumference and coronary heart disease for 1380 women aged 35-65 followed for 10 years

\begin{tabular}{|c|c|c|c|c|}
\hline $\begin{array}{l}\text { Centile (thigh } \\
\text { circumference in } \\
\mathrm{cm} \text { ) }\end{array}$ & Model 1* & Model $2 \dagger$ & Model $3 \ddagger$ & Model 4ף \\
\hline $2.5(46.0)$ & 2.20 (1.08 to 4.49$)$ & $4.56(1.30$ to 16.06$)$ & 4.65 (1.22 to 17.72$)$ & $2.45(0.52$ to 11.67$)$ \\
\hline $5(48.0)$ & 1.75 (1.01 to 3.04$)$ & 3.11 (1.15 to 8.36$)$ & $3.50(1.29$ to 9.5$)$ & $2.26(0.72$ to 7.13$)$ \\
\hline $10(49.5)$ & 1.48 (0.91 to 2.39$)$ & 2.34 (1.03 to 5.31$)$ & $2.82(1.28$ to 6.21$)$ & 2.12 (0.88 to 5.11$)$ \\
\hline $25(52.0)$ & 1.16 (0.77 to 1.76$)$ & 1.51 (0.84 to 2.72 ) & $1.92(1.12$ to 3.30$)$ & 1.77 (1.01 to 3.11$)$ \\
\hline $50(55.5)$ & 1 & 1 & 1 & 1 \\
\hline $75(59.5)$ & 1.00 (0.58 to 1.73$)$ & $0.76(0.37$ to 1.55$)$ & 0.55 (0.28 to 1.08$)$ & $0.54(0.27$ to 1.09$)$ \\
\hline $90(63.5)$ & 0.97 (0.46 to 2.06$)$ & 0.59 (0.20 to 1.72$)$ & $0.48(0.17$ to 1.31$)$ & 0.54 (0.18 to 1.61$)$ \\
\hline $95(66.5)$ & 0.95 (0.30 to 2.95$)$ & 0.49 (0.11 to 2.23$)$ & 0.50 (0.11 to 2.19$)$ & 0.66 (0.13 to 3.28$)$ \\
\hline $97.5(68.5)$ & 0.93 (0.21 to 4.13$)$ & 0.43 (0.06 to 2.90$)$ & 0.52 (0.08 to 3.44$)$ & 0.77 (0.10 to 5.86$)$ \\
\hline
\end{tabular}

*Adjusted for smoking, physical activity, education, and menopause.

†Additionally to * adjusted for body fat percentage and body height.

$\ddagger$ Additionally to * adjusted for BMI (body mass index) and waist circumference.

IAdditionally to $\ddagger$ adjusted for alcohol, systolic blood pressure, total cholesterol, and triglycerides.

strong predictive value in relation to mortality and cardiovascular disease, ${ }^{2324}$ making the possibility of residual confounding from exercise less likely.

Thresholds were evident in the range of $56-68 \mathrm{~cm}$, depending on end point and sex. For practical purposes we suggest the use a common threshold of 60 $\mathrm{cm}$. It should be noted that we might not have had sufficient power to show significant age differences in associations and thresholds, though we did not find much evidence for such differences.

Finally, lack of power might have prevented us from finding significantly stronger associations between thigh size and mortality for the smokers compared with non-smokers or for the associations in relation to coronary heart disease morbidity, especially among the women.

\section{Conclusions and policy implications}

We found that having smaller thighs was associated with development of cardiovascular morbidity and early mortality. The increased risk was independent of abdominal and general obesity and lifestyle and cardiovascular risk factors, such as blood pressure and lipids, related to early cardiovascular morbidity and mortality. Additionally, we found that the risk was more highly related to thigh circumference than

\section{WHAT IS ALREADY KNOWN ON THIS TOPIC}

Low BMI and low fat free mass are associated with early mortality

High BMI, waist circumference, waist to hip ratio, and low hip circumference are also associated with early mortality

\section{WHAT THIS STUDY ADDS}

Among both men and women, smaller thighs were associated with increased risk of cardiovascular disease and total mortality

A threshold effect for smaller thigh circumference was seen at around $60 \mathrm{~cm}$; above this threshold the protective effect of having larger thighs carried no further survival advantage

A focus on thigh circumference might help general practitioners to identify individuals who are at increased risk of early morbidity and mortality to waist circumference. In this regard, it is important to note that modifiable risk factors for abdominal obesity, or behaviours to selectively reduce waist circumference, are generally unknown. Thigh muscle mass, on the other hand, can be selectively increased by lower body physical activity, ${ }^{25-28}$ and a clear public health recommendation to change this risk factor can be easily communicated.

Our results suggest that there might be an increased risk of premature death related to thigh size. Furthermore, there seems to be a threshold effect of smaller thighs, but this needs further confirmation before the results can be generalised. On the other hand, the fact that more than half of the men and women aged 35-65 have thigh circumferences below the threshold is worrying. General practitioners could use thigh circumference as an early marker to identify patients at later risk of cardiovascular disease and early mortality.

These data were collected while BLH was at the Research Centre for Prevention and Health, Glostrup University Hospital, DK-2600 Glostrup, Denmark.

Contributors: BLH planned the study and is guarantor. PF undertook all statistical analyses. Both authors contributed to reporting the work.

Funding: The study was funded by the Danish Medical Research Council. Both researchers were independent of the funding agency.

Competing interests: None declared.

Ethical approval: This study was approved by the ethics committee for the Copenhagen County and is in accordance with the Helsinki II declaration on human rights. All participants in the study signed a letter of informed consent.

1 Waaler HT. Hazard of obesity-the Norwegian experience. Acta Med Scand Suppl 1988;723:17-21.

2 Heitmann BL, Erikson H, Ellsinger BM, Mikkelsen KL, Larsson B. Mortality associated with body fat, fat-free mass and body mass index among 60-year-old Swedish men-a 22-year follow-up. The study of men born in 1913. Int / Obes Relat Metab Disord 2000;24:33-7.

3 Zhu S, Heo M, Plankey M, Faith MS, Allison DB. Associations of body mass index and anthropometric indicators of fat mass and fat free mass with all-cause mortality among women in the first and second national health and nutrition examination surveys follow-up studies. Ann Epidemiol 2003;13:286-93.

4 Lissner L, Bjorkelund C, Heitmann BL, Seidell JC, Bentsson C. Larger hip circumference independently predicts health and longevity in a Swedish female cohort. Obesity Res 2001;9:644-6.

5 Heitmann BL, Frederiksen P, Lissner L. Hip circumference and cardiovascular morbidity and mortality in men and women. Obes Res 2004;12:482-7.

6 Bigaard J, Frederiksen K, Tjønneland A, Thomsen BL, Overvad K, Heitmann BL, et al. Waist and hip circumferences and all-cause mortality: usefulness of the waist-to-hip ratio? Int J Obesity 2004; $28: 741-7$

7 Snijder MB, Dekker JM, Visser M, Bouter LM, Stehouwer CV, Yudkin JS, et al. Trunk fat and leg fat have independent and opposite associations with fasting and postload glucose levels: the Hoorn study. Diabetes Care 2004;27:372-7.

8 Sacchetti M, Olsen DB, Saltin B, van Hall G. Heterogeneity in limb fatty acid kinetics in type 2 diabetes. Diabetologia 2005;48:938-45.

9 Olsen DB, Sacchetti M, Dela F, Ploug T, Saltin B. Glucose clearance is higher in arm than leg muscle in type 2 diabetes. J Physiol 2005;565:555-62.

10 Marquis K, Debigaré R, Lacasse Y, LeBlanc P, Jobin J, Carrier G, Maltais F. Mid-thigh muscle cross-sectional area is a better predictor of mortality than body mass index in patients with chronic obstructive pulmonary disease. Am J Respir Crit Care Med 2002;166:809-13.

11 Tanko LB, Bruun JM, Alexandersen P, Bagger YZ, Richelsen B, Christiansen $C$, et al. Novel associations between bio-available estradiol and adipokines in elderly women with different phenotypes of obesity. Implications for atherogenesis. Circulation 2004;110:2246-52.

12 Brotman DJ, Girod JP. Can glucocortiocoid homeostasis explane the antiatherogenic effect of peripheral adiposity? Circulation 2003;108:e61. 
13 McCarty MF. A paradox resolved: the postprandial model of insulin resistance explains why gynoid adiposity appears to be proctective. Med Hypotheses 2003;61:173-6.

14 Snijder MB, Visser M, Dekker JM, Goodpaster BH, Harris TB, Kritchevsky SB, et al. Low subcutaneous thigh fat is a risk factor for unfavourable glucose and lipid levels, independently of high abdominal fat. The health ABC study. Diabetologia 2005;48:301-8.

15 Heitmann BL. Body fat in the adult Danish population aged 35-65 years: an epidemiological study. Int J Obesity 1991;15:535-45.

16 Jensen HK, Jørgensen T. Incidence of gallstones in a Danish population. Gastroenterology 1991;100:790-4.

17 Heitmann BL. Prediction of body water and fat in adult Danes from measurement of electrical impedance. A validation study. Int J Obesity 1990;14:789-802.

18 World Health Organization. Measuring obesity—classification and description of anthropometric data. Report on a WHO consultation of the epidemiology of obesity. Warsaw 21-23 October 1987. Copenhagen: WHO,

1989. (Nutrition Unit document, EUR/ICP/NUT 123.)

19 Korn EL, Graubard BI, Midthune. Time-to-event analysis of longitudinal follow-up of a survey: choice of the time-scale. Am J Epidemiol 1997;145:72-80.

20 R Development Core Team. R: A language and environment for statistical computing. Vienna: R Foundation for Statistical Computing, 2005. www.R-project.org
21 Therneau TM, Grambsch PM. Modeling survival data: extending the Cox model. New York: Springer, 2000.

22 Grimby G, Wilhelmsen L, Bjorntorp P, Saltin B, Tibblin G. Habitual physical activity, aerobic power and blood lipids. In: Pernow E, Saltin B, eds. Muscle metabolism during exercise. New York: Plenum Press, 1979:469-81.

23 Andersen LB, Schnohr P, Schroll M, Heim HO. All-cause mortality associated with physical activity during leisure time, work sports, and cycling to work. Arch Intern Med 2000;160:1621-8.

24 Hippe M, Vestbo J, Hein HO, Borch-Johnsen K, Jensen G, Sørensen TI. Familial predisposition and susceptibility to the effect of other risk factors for myocardial infarction. J Epidemiol Community Health 1999;53:269-76.

25 Evans WJ. Reversing sarcopenia: how weight training can build strength and vitality. Geriatrics 1996;51:46-7.

26 McCartney N, Hicks AL, Martin J, Webber CE. Long-term resistance training in the elderly: effects on dynamic strength, exercise capacity, muscle, and bone. J Gerontol A Biol Sci Med Sci 1995;50:B97-104.

27 Miller JP, Pratley RE, Goldberg AP, Gordon P, Rubin M, Treuth MS, et al. Strength training increases insulin action in healthy 50 - to 65yr-old men. J Appl Physiol 1994;77:1122-7.

28 Goodpaster BH, Chomentowski P, Ward BK, Rossi A, Glynn NW, Delmonico MJ, eta l. Effects of physical activity on strength and skeletal muscle fat infiltration in older adults: a randomized controlled trial. J Appl Physiol 2008;105:1498-503.

Accepted: 30 May 2009 